\title{
Effects of theobromine addition on chemical and mechanical properties of a conventional glass ionomer cement
}

\author{
Fabricio Marcelo Cevallos González ${ }^{1,2}$. Erika Michele dos Santos Araújo ${ }^{3}$ Maria Regina Lorenzetti Simionato ${ }^{4}$. \\ Luciana Kfouri Siriani ${ }^{5} \cdot$ Ana Del Carmen Armas Vega ${ }^{2} \cdot$ Igor Studart Medeiros ${ }^{6}$. Adriana Bona Matos ${ }^{7}$ (1)
}

Received: 7 August 2018 / Accepted: 12 January 2019 / Published online: 6 February 2019

(c) The Author(s) 2019

\begin{abstract}
In vitro effect of $1 \%$ theobromine addition on the physical and chemical properties of conventional glass ionomer (GIC) cement was investigated. Conventional GIC (GIC-C) and 1\% theobromine added to GIC (GIC-THEO) specimens were compared regarding the microhardness $(n=10)$, sorption $(n=5)$, solubility $(n=5)$, color change $(n=10)$, fluoride release in saliva $(n=10)$ and the amount of biofilm deposition $(n=20)$. Compared against conventional GIC, adding $1 \%$ theobromine increased microhardness $(p<0.05)$, while its sorption, solubility, color and fluoride release to saliva $(p>0.05)$ remained unchanged. On the other hand, Streptococcus mutans biofilm amount deposited on its surface decreased statistically when theobromine was added to GIC $(p<0.05)$. Based on the results, it could be concluded that $1 \%$ theobromine addition to GIC can be a good strategy as it keeps some of its properties and improves microhardness and biofilm deposits strengthening its role in the preventive approach of dentistry.
\end{abstract}

Keywords Theobromine $\cdot$ Glass ionomer $\cdot$ Chemical properties $\cdot$ Mechanical properties $\cdot$ Biological properties

\section{Introduction}

Contemporary minimal intervention strategy targets professional care based on early detection of carious lesions and a noninvasive treatment approach. In this context, the use

Adriana Bona Matos

bona@usp.br

Inter Institutional PhD Program at School of Dentistry of University of São Paulo (USP), São Paulo, SP, Brazil

2 School of Dentistry, Central University of Ecuador, Quito, Ecuador

3 Department of Operative Dentistry, School of Dentistry, University of São Paulo (USP), São Paulo, SP, Brazil

4 Department of Microbiology, Institute of Biomedical Sciences, University of São Paulo (USP), São Paulo, SP, Brazil

5 Department of Operative Dentistry, School of Dentistry, University of São Paulo (USP), São Paulo, Brazil

6 Department of Biomaterials and Oral Biology, School of Dentistry, University of São Paulo, São Paulo, SP, Brazil

7 Department of Operative Dentistry, School of Dentistry, University of São Paulo (USP), Av. Prof. Lineu Prestes 2227, Cidade Universitária, São Paulo, SP CEP 05508-000, Brazil of glass ionomer cement (GIC) as a restorative material, as well as ITR technique (interim therapeutic restorations), plays a fundamental role due to some of its properties, such as ionic bonds between the carboxylic groups of the polyacid molecules and calcium ions of enamel and dentine; anti-cariogenic properties; and fluoride release to the oral environment (Sidhu and Nicholson 2016). The latter not only favors remineralization but also increases enamel and dentine resistance to demineralization, preventing secondary lesions (Hafshejani et al. 2017). On the other hand, other properties, such as microhardness, tensile strength, abrasion, poor polishing and esthetics limit its use (Sidhu and Nicholson 2016; Hafshejani et al. 2017).

Studies have focused on the inclusion of plant- and/or fruit-based agents into restorative materials (Zhao et al. 2014; Amaechi et al. 2013; Osawa et al. 2001) especially in the prevention of caries. In particular, studies reported that Theobroma cacao, with its high amounts of flavonoids and polyphenols obtained from both bark and seeds, provides bacteriostatic and remineralizing effects that inhibit biofilm progression by reducing the activity of Streptococcus mutans (S. mutans) and consequently decreasing caries (Percival et al. 2006; Amaechi et al. 2013; Zhao et al. 2014). 
Studies demonstrate the efficacy of cocoa bean extract in preventing growth and development of cariogenic bacteria in the oral environment, a process that involves the reduction of acid production and glucan synthesis by $S$. mutans, with inhibitory activity in glucosyltransferase (Matsumoto et al. 2004; Zhao et al. 2014). There is also scientific evidence concerning the antioxidant capacity of certain polyphenolic compounds, flavonoids and cocoa trace elements in reducing the inflammatory activity of cytokines (Percival et al. 2006). It is also worth mentioning that other cocoa components, such as oleic and linoleic acids, have antibacterial inhibitory action against $S$. mutans (Ooshima et al. 2000; Osawa et al. 2001). Other in vitro studies reported that alkaloids obtained from cocoa seeds or bark have the ability to remineralize enamel through the formation of apatite and increase in crystal size, creating a harder and acid dissolution-resistant enamel (Kargul et al. 2012; Amaechi et al. 2015; Lippert 2017; Simmons et al. 2016).

In this perspective, theobromine could be considered an additional choice to fluoride compounds, providing greater antibacterial, remineralization or desensitization efficacy (Kargul et al. 2012). When added to dentifrices, theobromine produces apparent dentinal tubules obliteration, which might reduce sensitivity (Amaechi et al. 2015; Lippert 2017).

Thus, due to promising results when added to other dental materials (Osawa et al. 2001; Matsumoto et al. 2004; Percival et al. 2006; Ferrazano et al. 2009; Kargul et al. 2012; Amaechi et al. 2015; Lippert 2017), this in vitro study evaluated the addition of theobromine to GIC in an attempt to increase its anti-cariogenic effects without altering its physical and chemical properties. This innovative material could be established as an additional strategy for caries treatment.

The aim of this study was to evaluate the in vitro effects of the addition of $1 \%$ theobromine to conventional glass ionomer cement on microhardness, sorption, solubility, color, and fluoride release in artificial saliva and on biofilm formation by $S$. mutans. The null hypothesis tested was that the addition of theobromine does not interfere in GIC properties, such as microhardness, color, sorption, solubility, antimicrobial ability and fluoride release.

\section{Materials and methods}

In this study, a conventional glass ionomer cement, GIC (Gold Fuji 9, GC Corp, Japan, Lot Number 1701241), was used as control (GIC-C). The experimental compound (GIC-THEO) was obtained by incorporating $1 \%$ per weight of theobromine (Sigma-Aldrich, Darmstadt, Germany), weighed on a $0.01 \mathrm{mg}$ precision scale of (ATX 224, Shimadzu, Japan), into the GIC powder. This concentration was used in a pilot study, considering the higher concentration of theobromine incorporated that maintained the shiny appearance of the surface mixture.

\section{Specimen preparation}

Round matrices of three different dimensions (diameter $\times$ thickness, in millimeters) were used: Teflon split $(8.6 \times 1.65)$ for the fluoride release; aluminum $(12 \times 1)$ for biofilm formation; and aluminum $(15 \times 1)$ for microhardness, color, sorption and solubility tests.

The materials were prepared at a powder-to-liquid ratio of $1: 1$, with complete mixing for $30 \mathrm{~s}$ at $23^{\circ} \mathrm{C}$ (room temperature). Then, the materials were inserted into their respective matrices with a Centrix syringe (Maquira, Maringá, Paraná, Brazil) and pressed by a polyester strip. Specimens were stored at $37{ }^{\circ} \mathrm{C}$ for $24 \mathrm{~h}$ under $100 \%$ relative humidity. After this period, the specimens were removed from matrices.

\section{Microhardness test $(n=10)$}

Five indentations were performed on each specimen using $25 \mathrm{~g}$ load for $30 \mathrm{~s}$ (Ibrahim et al. 2017) with a minimum distance of $100 \mu \mathrm{m}$ between each Vickers indentation (HMV-G series 21, Micro Vickers Hardness Tester, Shimadzu, Kyoto, Japan). Final hardness mean (in VHN) was calculated for each specimen.

\section{Sorption and solubility assay $(n=10)$}

Sorption and solubility tests followed 4049 ISO guidelines (2009). The specimens were stored in a desiccator with silica gel, and then incubated in an oven (Orion 520, Fanem, Sao Paulo, Brazil) at $37^{\circ} \mathrm{C}$ for $22 \mathrm{~h}$ and in a desiccator at $23{ }^{\circ} \mathrm{C}$ for $2 \mathrm{~h}$. Then, each specimen was weighed with a $0.01 \mathrm{mg}$ precision analytical balance (ATX 224, Shimadzu, Japan) every $24 \mathrm{~h}$ until a constant mass was reached $\left(\mathrm{m}_{1}\right)$.

Diameter and thickness were measured with a digital caliper (MPI/E-101, Mytutoyo, Tokyo, Japan) to calculate both area $\left(\mathrm{mm}^{2}\right)$ and volume $\left(\mathrm{mm}^{3}\right)$ of the specimen. The specimens were then individually and vertically immersed in $10 \mathrm{~mL}$ of distilled water for 7 days at $37{ }^{\circ} \mathrm{C}$. After this period, specimens were rinsed with distilled water and dried with air spray for $15 \mathrm{~s}$ and weighed $\left(\mathrm{m}_{2}\right)$ after $1 \mathrm{~min}$.

Subsequently, the specimens were submitted to the same drying process described to obtain the $\left(\mathrm{m}_{1}\right)$ until a new constant mass was obtained $\left(\mathrm{m}_{3}\right)$.

Sorption and solubility $\left(\mu \mathrm{g} / \mathrm{mm}^{3}\right)$ were calculated by the following equations:

$\mathrm{Wsp}=\frac{m 2-m 3}{V}$,

$\mathrm{Wsl}=\frac{m 1-m 3}{V}$, 
where Wsp corresponds to sorption; Wsl corresponds to solubility; $m 1$ is the conditioned mass (before immersion in water); $m 2$ is the mass (mg) after immersion in water for 7 days; $m 3$ is the mass $(\mathrm{mg})$ reconditioned; $V$ is the volume of the specimen $\left(\mathrm{mm}^{3}\right)$.

\section{Color change $(\Delta E)(n=10)$}

According to ISO 7491 guidelines (2000), a color difference test was performed between the GIC-THEO and GIC-C groups. Using a spectrophotometer (CM3700A, Konica Minolta, Tokyo, Japan), specimen colors were recorded based on the CIELab colorimetric system. Color differences $(\Delta \mathrm{E})$ were determined by the following equation using a standard white background:

$\Delta E=\left[\left(L-L_{0}\right)^{2}+\left(a-a_{0}\right)^{2}+\left(b-b_{0}\right)^{2}\right]^{1 / 2}$,

where the values for $L, a$, and $b$ parameters were obtained from GIC-THEO specimens and $L_{0}, a_{0}, b_{0}$ parameters from the GIC-C.

\section{Antimicrobial ability $(n=20)$}

Streptococcus mutans biofilm quantification was based on previous studies (Waterhouse and Russell 2006; Nomura et al. 2009; Standar et al. 2010) with some amendments. GIC-C and GIC-THEO specimens were fixed with glue inside a 24-well culture plate. After sterilization with gamma radiation (25 kGy), S. mutans strains (UA 159), obtained from frozen stock collection, were activated on Tryptic Soy Agar (TSA, Difco, Leeuwarden, The Netherlands) at $37^{\circ} \mathrm{C}$ for $16 \mathrm{~h}$ under microaerophilic/anaerobic conditions. After this period, the colonies were scraped and transferred to Tryptic Soy Broth (TSB, Difco, Leeuwarden, The Netherlands) medium until an optical density $\left(\mathrm{OD}_{600}\right)$ of 0.3 , detected by a spectrophotometer (Biophotometer, Eppendorf, Hamburg, Germany), was achieved. Then, colonies were stored under microaerophilic conditions for $3 \mathrm{~h}$. All procedures were performed inside a laminar air-flow chamber under aseptic environment.

Then, the cultures were centrifuged at $5000 \times g$ for $5 \mathrm{~min}$, and the supernatant was resuspended in Biofilm Medium (BM0) (Loo et al. 2000) plus 1\% sucrose as a carbohydrate source to compose a standard microbial inoculum with $\mathrm{OD}_{600}=0.8$, approximately $1 \times 10^{10} \mathrm{CFU} / \mathrm{mL}$. Five aliquots of $1 \mathrm{~mL}$ were added to each well, and the samples were incubated under microaerophilic conditions at $37^{\circ} \mathrm{C}$ for $3 \mathrm{~h}$. Every $24 \mathrm{~h}, 1 \%$ sucrose enriched medium was replaced, over the course of 24, 48, 72 and $96 \mathrm{~h}$ time points.

For biomass evaluation, culture medium was removed, and the biofilm was statically stained with $500 \mu \mathrm{L}$ of $0.4 \%$ safranin (Sigma, Gillinghan, England) for $15 \mathrm{~min}$ at room temperature in the presence of light. Specimens were rinsed three times by soaking in distilled water. Then, $500 \mu \mathrm{L}$ of 95\% ethanol was applied for 15 min to perform biofilm discoloration. After this period, five $50 \mu \mathrm{L}$ aliquots of ethanol solution from each well were transferred to 96-well plates and assayed on an ELISA reader (Microplate Reader Model 680, Bio-Rad, Foster City, California, USA) at $490 \mathrm{~nm}$ $\left(\mathrm{A}_{490}\right)$. Thus, five readings were obtained from each experimental well, in a total of one hundred readings.

\section{Fluoride release $(n=10)$}

Fluoride release test was performed as previously described (Carvalho and Cury 1999; Hayacibara et al. 2004; Nigam et al. 2009) with some amendments. The specimens were produced according to ISO 7489 standard guidelines (1986). Prior to the initial hardening of GIC-C and GIC-THEO, a piece of dental floss was added within the specimen so that it could be suspended in the solution.

After the initial sampling, specimens were removed from the matrices and placed in an oven (Orion, Fanen, Brazil) $\left(37^{\circ} \mathrm{C}, 100 \%\right.$ relative humidity) for $24 \mathrm{~h}$. Subsequently, each specimen was rinsed in $1 \mathrm{~mL}$ of deionized water and immersed in $1 \mathrm{~mL}$ of sterile artificial saliva [Ca $1.5 \mathrm{mM}$ $\left(\mathrm{CaCl}_{2} 0.1665 \mathrm{~g} / \mathrm{L}\right) ; 0.9 \mathrm{mM} \mathrm{PO}{ }_{4}\left(\mathrm{NaH}_{2} \mathrm{PO}_{4} 0.133 \mathrm{~g} / \mathrm{L}\right) ; \mathrm{KCl}$ $150 \mathrm{mM}(\mathrm{KCl} 11.184 \mathrm{~g} / \mathrm{L})$; Tris buffer $20 \mathrm{mM}(2.4228 \mathrm{~g} / \mathrm{L})$ and $0.02 \% \mathrm{NaN}_{3}$ ], and $\mathrm{pH}$ was buffered to 7.0 .

Specimens were immersed in artificial saliva and stored in a shaker (Nova Ética, Model 430 RDB Incubator, São Paulo, Brazil) at $37^{\circ} \mathrm{C}$. Every $24 \mathrm{~h}$, specimens were rinsed with $1 \mathrm{~mL}$ of deionized water and stored in $1 \mathrm{~mL}$ of artificial saliva, for 15 days. Control was performed on pure artificial saliva.

The fluoride electrode (Mettler-Toledo International Inc., Greifensee, Zurich, Switzerland, Model T50 Perfect ION Fluoride Combination) was previously calibrated with a series of five standard solutions $(0.065,0.125,0.250,0.500$ and $1000 \mathrm{mg} \mathrm{F}^{-} / \mathrm{mL}$ ) in triplicate. A 1:10 ratio of storage solution (TISAB III, total ionic strength adjustment buffer, Orion, Boston, MA, USA) was analyzed in duplicate. The results obtained per specimen were divided by the area of the specimen and expressed in $\mu \mathrm{g} / \mathrm{cm}^{2}$.

\section{Statistical analysis}

One-way ANOVA compared GIC-C and GIC-THEO regarding microhardness, sorption, solubility and color change (Minitab 17, Minitab Inc, Pennsylvania, USA), complemented by Tukey's test for comparison, at $95 \%$ level of significance $(p<0.05)$.

Statistical evaluation of antimicrobial activity and fluoride release was performed by two-way ANOVA and 
Tukey's test, at 5\% significance level. For antimicrobial ability, the following variables were tested: GIC (GIC-C and GIC-THEO) and time points (24, 48, 72 and $96 \mathrm{~h}$ ); for fluoride release, the factors were: GIC (GIC-C and GIC-THEO) and time points ( $1-15$ days).

\section{Results}

\section{Microhardness}

ANOVA detected a statistically significant difference between GIC-THEO and GIC-C $(p=0.00)$, with increased microhardness for the GIC-THEO group.

\section{Sorption and solubility assay}

ANOVA did not reveal a statistically significant difference between the values of sorption $(p=0.99)$ and solubility $(p=0.86)$ between the tested groups (Table 1$)$.

\section{Color change}

The color change $(\Delta E)$ between GIC-C and GIC-THEO was $1.38 \pm 0.22$, indicating that the addition of theobromine did not compromise the color of GIC.

\section{Fluoride release}

Concerning fluoride release, ANOVA detected a statistically significant difference for tested time points $(p=0.00)$, while no statistically significant differences were detected for GIC $(p=0.529)$ and for variables interaction $(p=0.282)$. The addition of $1 \%$ theobromine did not compromise the fluoride release of GIC. Figure 1 clearly shows the reduction in fluoride released to saliva as a function of time, despite GIC tested. The concentration was strongly reduced from day 2 to 5 , whereas the concentrations remained statistically similar from day 5 to 15 .

\section{Antimicrobial ability}

Regarding antimicrobial activity, ANOVA detected a statistically significant difference for time points $(p=0.001)$ and GIC $(p=0.005)$. However, the interaction between these factors was not statistically significant $(p=0.152)$. Regarding time points, the lowest amount of biofilm was deposited after $24 \mathrm{~h}$, while the largest amount of biofilm was deposited after $96 \mathrm{~h}$. Intermediate amounts of biofilm were detected at 48 and $72 \mathrm{~h}$, with no statistically significant difference between them. Lower amounts of biofilm were detected in GIC-THEO samples than in GIC-C, indicating that the inclusion of $1 \%$ theobromine increased the antimicrobial ability of GIC.

\section{Discussion}

In this study, the null hypothesis was partially accepted, since some properties of GIC were modified by the addition of theobromine. This is the first study that added theobromine to a dental cement, but this alkaloid has already showed positive results as a remineralizing substance
Table 1 Microhardness, sorption, solubility results mean and standard deviation of experimental groups

\begin{tabular}{llll}
\hline Experimental groups & Microhardness $(\mathrm{VHN})$ & Sorption $\left(\mu \mathrm{g} / \mathrm{mm}^{3}\right)$ & Solubility $\left(\mu \mathrm{g} / \mathrm{mm}^{3}\right)$ \\
\hline GIC-THEO & $60.96 \pm 6.19 \mathrm{~B}$ & $0.13 \pm 0.036 \mathrm{~A}$ & $0.018 \pm 0.13 \mathrm{~A}$ \\
GIC-C & $35.33 \pm 3.90 \mathrm{~A}$ & $0.13 \pm 0.011 \mathrm{~A}$ & $0.017 \pm 0.003 \mathrm{~A}$ \\
\hline
\end{tabular}

Averages that do not share a letter are significantly different

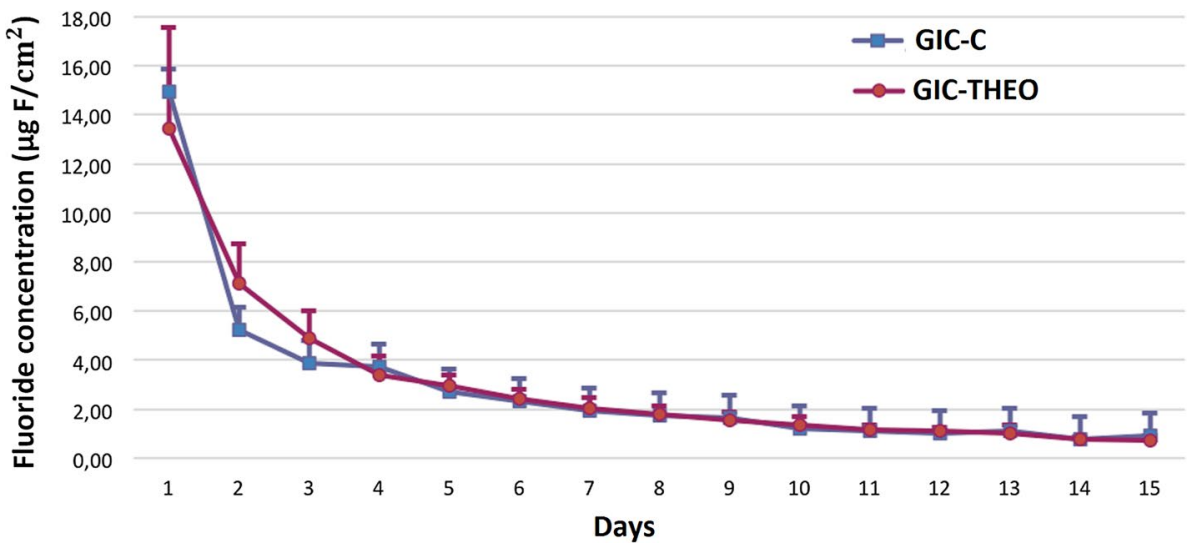

Fig. 1 Fluoride dosage ( $\mu \mathrm{g} \mathrm{F}$ / $\mathrm{cm}^{2}$ ) in artificial saliva for GIC-C and GIC-THEO 
added to mouth rinses and dentifrices (Matsumoto et al. 2004; Kargul et al. 2012; Gazzani et al. 2012; Badiyani et al. 2013; Amaechi et al. 2013, 2015; Lippert 2017), providing the rationale for this study.

The literature reports opposing results with respect to the active component added to GIC. There was a considerable decrease in Vickers hardness when GIC was previously immersed in buffer medium containing acidulated fluoride phosphate (AFP) and $\mathrm{TiF}_{4}$ (Topaloglu-Ak et al. 2012) or when adhesive/nanofiller monomers were added to GIC (Bagheri et al. 2013). On the other hand, due to the incorporation of $\mathrm{N}$-vinylcaprolactam (Moshaverinia et al. 2011) into conventional glass ionomers, no hardness modification was detected.

GIC-THEO results showed an increased microhardness, when compared to GIC-C, in accordance with another study that added proline and $0.1 \%$ epigallocatechin-3-gallate (EGCG) to a conventional GIC (Ansari et al. 2013; Amaechi et al. 2013). Researchers (Hu et al. 2013) suggest that by adding EGCG to GIC, an increased chelation between phenolic hydroxyl and carboxyl groups in GIC occurred, leading to an enhanced formation of polysaccharides and crosslinks, modifying the material into a more complex structure. In addition, gaps between GIC particles can be reduced if a higher acid amount reacts with the powder of GIC. These modifications together increased the amount of molecular bonds on the surface of the material, leading to an increase in microhardness ( $\mathrm{Hu}$ et al. 2013; Zoergiebel and Ilie 2013). As theobromine also belongs to the family of polyphenols, we suggest that the addition of theobromine to the GIC may exert a similar effect as the inclusion of EGCG with regard to microhardness outcomes.

Sorption and solubility assays detected similar results for GIC-THEO and GIC-C. However, other studies detected higher water sorption and greater microleakage when other substances such as $1 \%$ natural propolis, $2 \%$ lyophilized propolis (Troca et al. 2011), or 0.06, 0.08 and $0.1 \%$ per weight of silica particles (Felemban and Ebrahim 2016) were utilized in modified GICs. In these studies, (Troca et al. 2011; Felemban and Ebrahim 2016), compressive and tensile strengths were preserved. It is fundamental to consider that propolis, a natural resin-like material, and silica particles are primarily focused on the context of increasing material strength, but this focus should not compromise other properties. Additionally, the addition of $2.5 \%$ of chlorhexidine diacetate with $2.5 \%$ of cetrimide yielded an increased solubility of GIC (Korkmaz et al. 2013). Therefore, since the result of the chemical reaction of the GIC with theobromine did not change the sorption and solubility of the material, if sufficient additional properties are not compromised, its use could be considered safe.
The addition of theobromine did not compromise the color of GIC, as a study that evaluated the addition of chlorhexidine (CHX) and resin to GICs (Prabhakar et al. 2013) observed a greater color stability for materials modified by $\mathrm{CHX}$ than by resin. Literature indicates that values of $\Delta \mathrm{E}$ lower than 1 are considered non-perceptible to the human eye, while values between 1.1 and 3.3 are clinically acceptable (Zhou et al. 2018). Thus, our results are considered favorable in support of the innovation proposed in this manuscript, as the slight color change presented by GIC-THEO is clinically acceptable and does not compromise its application.

In relation to the amount of biofilm formed by $S$. mutans, a considerable decrease in biofilm was detected in GIC-THEO samples. Similar results were observed when the inclusion of $0.1 \%$ epigallocatechin-3-gallate (EGCG) was tested in a conventional GIC, with a reduction in the amount of biofilm formed on the modified GIC specimens (Hu et al. 2013). It is suggested that the antibacterial action of theobromine may be related to additional factors, such as the reduction of bacterial adhesion (Percival et al. 2006; Hu et al. 2013; Sudharsana and Srisakthi 2015), inhibition of glucosyltransferase enzyme secreted by cariogenic bacteria, which reduces biofilm formation and acid production of S. mutans (Hu et al. 2013), suppression of saliva and bacterial amylase activity, causing alteration in carbohydrate metabolism, which reduces the rate of acid production by $S$. mutans or causing irreversible damage to the cytoplasmic membrane of bacteria (Matsumoto et al. 2004). Thus, we consider that the addition of theobromine empowered the antimicrobial effect of GIC.

Fluoride release after the addition of $1 \%$ theobromine to GIC did not change, as similarly observed when $0.1 \%$ epigallocatechin-3-gallate (EGCG) (Hu et al. 2013) was added to GIC. As both of these active components are from the polyphenol family, we suggest that a strong anticariogenic action could be a positive attribute of the use of GICs.

Since the solubility was not changed for GIC-THEO, the fluoride ion release for the medium curve meets that of GIC-C, with higher release rates in the first $24 \mathrm{~h}$ (Prabhakar et al. 2013) and a reduction over the storage period, and with a tendency to stabilize after 5 days. An additional study (Amaechi et al. 2013) reported that this stabilized release occurs due to a decrease in the concentration of the carboxyl groups $(\mathrm{COOH})$.

The limitation of this in vitro study mainly consists of the absence of similar studies to challenge and corroborate the obtained results. In this sense, as theobromine and EGCG are each substances from the polyphenol family, we speculated that correlating our results with EGCG could be an interesting approach. Thus, it can be considered that the incorporation of $1 \%$ of theobromine into a conventional 
GIC can represent an interesting strategy to enhance microhardness and antimicrobial effects without compromising other tested properties. The stability of the improvements observed herein should be verified in longitudinal studies. It is important to note that we used a commercial GIC (GCGold Fuji 9, GC Corp, Japan) and a commercial theobromine compound (Sigma-Aldrich, Darmstadt, Germany) to compose our modified product and that no further characterization of the material was performed. Thus, our results are valid for the combination of these two products.

\section{Conclusion}

Because the addition of theobromine to GIC increased microhardness and reduced the amount of biofilm formed over the material surface, did not interfere with sorption, solubility, color; and fluoride released to saliva, it can be considered a valid alternative approach to improve the performance of GIC.

Acknowledgements We thank Professor Fabio Daumas Nunes, for supporting the ion release challenge specimen preparation on the Biomolecular Facility at School of Dentistry, University of São Paulo (FOUSP) and Professor Cinthia Tabchoury for supporting the fluoride dosage assay at School of Dentistry, University of Campinas (FOP-UNICAMP).

\section{Compliance with ethical standards}

Conflict of interest The authors declare no conflict of interest.

Open Access This article is distributed under the terms of the Creative Commons Attribution 4.0 International License (http://creativeco mmons.org/licenses/by/4.0/), which permits unrestricted use, distribution, and reproduction in any medium, provided you give appropriate credit to the original author(s) and the source, provide a link to the Creative Commons license, and indicate if changes were made.

\section{References}

Amaechi BT, Porteous N, Ramalingam K, Mensinkai PK, Ccahuana Vasquez RA, Sadeghpour A et al (2013) Remineralization of artificial enamel lesions by theobromine. Caries Res 47(5):399-405

Amaechi BT, Mathews SM, Mensinkai PK (2015) Effect of theobromine-containing toothpaste on dentin tubule occlusion in situ. Clin Oral Investig 19(1):109-116

Ansari S, Moshaverinia M, Roohpour N, Chee WWL, Schricker SR, Moshaverinia A (2013) Properties of a proline-containing glass ionomer dental cement. J Prosthet Dent 110(5):408-413

Badiyani BK, Kumar A, Bhat PK, Sarkar S (2013) Chocolate disinfectant: effectiveness of cocoa bean husk extract on Streptococcus mutans in used toothbrushes. Int J Oral Care Res 1(1):7-10

Bagheri R, Taha NA, Azar MR, Burrow MF (2013) Effect of G-Coat Plus on the mechanical properties of glass-ionomer cements. Aust Dent J 58(4):448-453
Carvalho AS, Cury JA (1999) Fluoride release from some dental materials in different solutions. Oper Dent 24(1):14-19

Felemban NH, Ebrahim MI (2016) Effects of adding silica particles on certain properties of resin-modified glass-ionomer cement. Eur J Dent 10(2):225-229

Ferrazano GF, Amato I, Ingenito A, De Natale A, Pollio A (2009) Anti-cariogenic effects of polyphenols from plant simulant beverages (cocoa, coffee, tea). FitoterapiaJul 80(5):255-262. https ://doi.org/10.1016/j.fitote.2009.04.006

Gazzani G, Daglia M, Papetti A (2012) Food components with anticariesactivity. Curr Opin Biotechnol 23(2):153-159

Hafshejani TM, Zamanian A, Venugopal JR, Rezvani Z, Sefat F, Saeb MR, Vahabi H, Zarrintaj P, Mozafari M (2017) Antibacterial glass-ionomer cement restorative materials: a critical review on the current status of extended release formulations. J Control Release 28(262):317-328. https://doi.org/10.1016/j. jconrel.2017.07.041

Hayacibara MF, Ambrozano GMB, Cury JA (2004) Simultaneous release of fluoride and aluminum from dental materials in various immersion media. Oper Dent 29(1):16-22

Hu J, Du X, Huang C, Fu D, Ouyang X, Wang Y (2013) Antibacterial and physical properties of EGCG-containing glass ionomer cements. J Dent 41(10):927-934

Ibrahim MA, Priyadarshini BM, Neo J, Fawzy AS (2017) Characterization of Chitosan/ $/ \mathrm{TiO}_{2}$ nano-powder modified glass-ionomer cement for restorative dental applications. J Esthet Restor Dent 29(2):146-156

International Organization for Standardization (2009) ISO 4049: dentistry: polymer-based restorative materials. International Organization for Standardization, Switzerland

International Organization for Standardization (1986) ISO 7489: dental materials: dental glass polyalkenoate cements. International Organization for Standardization, Switzerland

International Organization for Standardization (2000) ISO 7491: dental materials: determination of colour stability. International Organization for Standardization, Switzerland

Kargul B, Özcan M, Peker S, Nakamoto T, Simmons WB, Falster AU (2012) Evaluation of human enamel surfaces treated with theobromine: a pilot study. Oral Health Prev Dent 10(3):275-282

Korkmaz FM, Tüzüner T, Baygin O, Buruk CK, Durkan R, Bagis B (2013) Antibacterial activity, surface roughness, flexural strength, and solubility of conventional luting cements containing chlorhexidine diacetate/cetrimide mixtures. J Prosthet Dent 110(2):107-115. https://doi.org/10.1016/s0022-3913(13)60349 $-2$

Lippert F (2017) The effects of fluoride, strontium, theobromine and their combinations on caries lesion rehardening and fluoridation. Arch Oral Biol 80:217-221

Loo CY, Corliss DA, Ganeshkumar N (2000) Streptococcus gordonii biofilm formation: identification of genes that code for biofilm phenotypes. J Bacteriol 182(5):1374-1382

Matsumoto M, Tsuji M, Okuda J, Sasaki H, Nakano K, Osawa K et al (2004) Inhibitory effects of cacao bean husk extract on plaque formation in vitro and in vivo. Eur J Oral Sci 112(3):249-252

Moshaverinia A, Ansari S, Roohpour N, Reshad M, Schricker SR, Chee WW (2011) Effects of $N$-vinylcaprolactam containing polyelectrolytes on hardness, fluoride release and water sorption of conventional glass ionomers. J Prosthet Dent 105(5):323-331

Nigam A, Jaiswal J, Murthy R, Pandey R (2009) Estimation of fluoride release from various dental materials in different media-an in vitro study. Int J Clin Pediatr Dent 2(1):1-8

Nomura R, Nakano K, Taniguchi N, Lapirattanakul J, Nemoto H, Grönroos L et al (2009) Molecular and clinical analyses of the gene encoding the collagen-binding adhesin of Streptococcus mutans. J Med Microbiol 58(4):469-475 
Ooshima T, Osaka Y, Sasaki H, Osawa K, Yasuda H, Matsumoto M (2000) Cariostatic activity of cacao mass extract. Arch Oral Biol 45(9):805-808

Osawa K, Miyazaki K, Shimura S, Okuda J, Matsumoto M, Ooshima $\mathrm{T}$ (2001) Identification of cariostatic substances in the cacao bean husk: their anti-glucosyltransferase and antibacterial activities. J Dent Res 80(11):2000-2004

Percival RS, Devine DA, Duggal MS, Chartron S, Marsh PD (2006) The effect of cocoa polyphenols on the growth, metabolism, and biofilm formation by Streptococcus mutans and Streptococcus sanguinis. Eur J Oral Sci 114(4):343-348

Prabhakar A, Pattanshetti K, Sugandhan S (2013) A comparative study of color stability and fluoride release from glass ionomer cements combined with chlorhexidine. Int J ClinPediatr Dent 6(1):26-29

Sidhu SK, Nicholson JW (2016) A review of glass-ionomer cements for clinical dentistry. J Funct Biomater 7(3):16. https://doi. org/10.3390/jfb7030016

Simmons JO, Meyers EJ, Lien W, Banfield RL, Roberts HW, Vandewalle KS (2016) Effect of surface treatments on the mechanical properties and antimicrobial activity of desiccated glass ionomers. Dent Mater 32(11):1343-1351. https://doi.org/10.1016/j.denta 1.2016.08.214

Standar K, Kreikemeyer B, Redanz S, Münter WL, Laue M, Podbielski A (2010) Setup of an in vitro test system for basic studies on biofilm behavior of mixed-species cultures with dental and periodontal pathogens. PLoS One 5(10):e13135

Sudharsana A, Srisakthi MD (2015) Tooth friendly chocolate. J Pharm Sci Res 7(1):49-50
Topaloglu-Ak A, Cogulu D, Ersin NK, Sen BH (2012) Microhardness and surface roughness of glass ionomer cements after APF and TiF4 applications. J Clin Pediatr Dent 37(1):45-51

Troca VBPB, Fernandes KBP, Terrile AE, Marcucci MC, de Andrade FB, Wang L (2011) Effect of green propolis addition to physical mechanical properties of glass ionomer cements. J Appl Oral Sci 19(2):100-105

Waterhouse JC, Russell RRB (2006) Dispensable genes and foreign DNA in Streptococcus mutans. Microbiology 152(6):1777-1788

Zhao W, Xie Q, Bedran-Russo AK, Pan S, Ling J, Wu CD (2014) The preventive effect of grape seed extract on artificial enamel caries progression in a microbial biofilm-induced caries model. J Dent 42(8):1010-1018

Zhou X, Wang S, Peng X, Hu Y, Ren B, Li M, Hao L, Feng M, Cheng L, Zhou X (2018) Effects of water and microbial-based aging on the performance of three dental restorative materials. J Mech Behav Biomed Mater 80:42-50. https://doi.org/10.1016/j.jmbbm .2018 .01 .023

Zoergiebel J, Ilie N (2013) Evaluation of a conventional glass ionomer cement with new zinc formulation: effect of coating, aging and storage agents. Clin Oral Investig 17(2):619-626

Publisher's Note Springer Nature remains neutral with regard to jurisdictional claims in published maps and institutional affiliations. 